\title{
Mothers' adherence to optimal infant and young child feeding practices in Uganda: a cross-sectional study [version 1; peer
} review: 3 not approved]

\author{
Zabinah Nabirye1, Frank Kiwanuka (iD)1,2, Zainah Nakaye (D1), Ivan Kamurasi (D1, \\ Agbele Alaba Tolulope (i) 3,4
}

${ }^{1}$ Institute of Public Health and Management, Clarke International University, Kampala, Uganda
2Department of Intensive Care Nursing, School of Nursing, Tehran University of Medical Sciences, Tehran, Iran
${ }^{3}$ Department of Basic Medical Science, College of Health Sciences and Technology Ijero Ekiti, Ijero, Nigeria
${ }^{4}$ School of Medicine, Tehran University of Medical Sciences, Tehran, Iran

V1 First published: 22 Jun 2018, 7:877

https://doi.org/10.12688/f1000research.15129.1

Latest published: 22 Jun 2018, 7:877

https://doi.org/10.12688/f1000research.15129.1

\section{Abstract}

Background: The benefits of adherence to optimal infant and young child feeding (IYCF) to both the mothers and their infants below two years are well documented. However, compliance to optimal IYCF practices has been noted to vary in different settings. This study sought to establish factors influencing mothers' adherence to optimal infant and young child feeding practices for babies below two years in Mpigi town council- Mpigi District.

Methods: The study was a cross-sectional study carried out among 264 mothers of babies between six months to two years of age attending postnatal care units of health facilities in Mpigi town council, Uganda: Mpigi Health Center (HC) IV and Kyaali HC III. Purposive sampling method was used to select the health centers while simple random sampling was then used to select the sample from the selected centers. A self-administered questionnaire was used to collect data. Data entry and analysis was performed using SPSS version 16.

Results: 264 participants were invited to participate in the study, $100 \%$ of these fully completed the survey. The majority of the mothers were aged 20 to 34 years (80.3\%). After scoring each participant using the four characteristics which included: initiation of breastfeeding within the first hour following birth, exclusive breastfeeding up to 6 months followed by continued breastfeeding with appropriate complementary foods upto 2 years and beyond, the majority of the participants were adherent (79.6\%) to IYCF practices while $20.4 \%$ were non adherent to IYCF practices.

Conclusion: A good estimate of adherence to optimal IYCF practices was revealed in this study. Sustaining well-established policies to support IYCF programmes is recommended to maintain optimal IYCF 
practices.

Keywords

Adherence, Mothers, Infant and Young Child Feeding, Uganda, Africa, Low and Middle-Income countries

Corresponding author: Frank Kiwanuka (f.kiwanuka1@gmail.com)

Author roles: Nabirye Z: Conceptualization, Data Curation, Investigation, Methodology, Project Administration, Writing - Original Draft Preparation, Writing - Review \& Editing; Kiwanuka F: Conceptualization, Data Curation, Formal Analysis, Investigation, Methodology, Project Administration, Writing - Original Draft Preparation, Writing - Review \& Editing; Nakaye Z: Validation, Writing - Original Draft Preparation, Writing - Review \& Editing; Kamurasi I: Methodology, Writing - Original Draft Preparation, Writing - Review \& Editing; Tolulope AA: Methodology, Writing - Original Draft Preparation, Writing - Review \& Editing

Competing interests: No competing interests were disclosed.

Grant information: The author(s) declared that no grants were involved in supporting this work.

Copyright: ( 2018 Nabirye $Z$ et al. This is an open access article distributed under the terms of the Creative Commons Attribution License, which permits unrestricted use, distribution, and reproduction in any medium, provided the original work is properly cited.

How to cite this article: Nabirye Z, Kiwanuka F, Nakaye Z et al. Mothers' adherence to optimal infant and young child feeding practices in Uganda: a cross-sectional study [version 1; peer review: 3 not approved] F1000Research 2018, 7:877 https://doi.org/10.12688/f1000research.15129.1

First published: 22 Jun 2018, 7:877 https://doi.org/10.12688/f1000research.15129.1 


\section{Introduction}

Optimal Infant and Young Child Feeding (IYCF) is crucial for survival across the entire childhood continuum. The World Health Organization (WHO) and the United Nations Children's Fund (UNICEF) have recommended initiation of exclusive breastfeeding from the time of birth up to 24 months of age ${ }^{1}$. Optimal feeding of infants from 0 to 5 months has been associated with significantly lower risk of all-cause and related mortality compared to partial or not breastfeeding at all ${ }^{1,2}$.

Estimates suggest that optimal IYCF practices could prevent approximately $12 \%$ of mortality in the under 5's annually. This accounts for about 800,000 lives in Low and Middle-Income Countries (LMICs) ${ }^{3}$.

Early initiation of optimal IYCF within the first hour following birth in the form of exclusive breastfeeding up to 6 months followed by continued breastfeeding for up to 2 years and beyond with appropriate complementary foods after completion of 6 months is the gold standard for optimal $\mathrm{IYCF}^{1,4}$.

Sub-Saharan African countries have one of the highest prevalence of breastfeeding at one year, however only $37 \%$ of infants less than 6 months are exclusively breastfed ${ }^{3,5}$. Various factors have been cited for the low optimal IYCF practices, including; socio-economic status ${ }^{6,7}$, home births, culture and poorly implemented and monitored strategies of regulating the marketing of breast-milk substitutes, feeding bottles and teats ${ }^{6-10}$. Other cited factors to non-adherence to optimal IYCF include; education levels, health providers' practices and market pressures to use breast milk substitutes and other nutritional supplements ${ }^{3,11}$.

The Uganda demographic and health survey ${ }^{12}$ noted that only $63 \%$ of infants younger than six months are exclusively breast fed and complementary foods are not introduced in a timely fashion for all children; $33 \%$ of children under five are stunted, with only $6 \%$ of children aged 6-23 months being appropriately fed ${ }^{12}$.

This study sought to establish the factors influencing mothers' adherence to optimal infant feeding practices for infants below the age of two years in Mpigi town council health facilities, Mpigi District, Uganda. Findings from this study provide country specific data on the extent of adherence to optimal IYCF practices. Such evidence is seminal to policy makers to sustain IYCF policies and programmes.

\section{Methods}

Study design and setting

This was a cross-sectional study carried out among mothers attending postnatal care units of health facilities in Mpigi town council, Uganda from May 2016 to August 2016. Mpigi district is located in the Central region of Uganda, 32 Kilometers West of Kampala Capital City along Masaka road. The study was conducted in two health centers: Mpigi Health Center (HC) IV and Kyaali HC III. Mpigi HC IV is the largest health facility in Mpigi District.

\section{Sampling procedure}

Mixed sampling methods were used. Purposive sampling was used to select the health centers. Simple random sampling was then used to select the sample from the selected centers. Mothers and caretakers of babies six months to two years of age were included in the study while as those who were participating in interventional breastfeeding studies were excluded from the study.

\section{Data collection methods}

Data was collected using a structured questionnaire (Supplementary File $1^{13}$ ). The questionnaire was developed through literature review. The tool consisted of three sections; section one assess sociodemographic data, section two assessed maternal and infant data, while section three assessed Healthcare related data. The tool was validated by 5 experts. The tool was pre-tested at Mulago National referral Hospital before data collection. The questionnaires were administered by research assistants to participants during Young Child Clinics (YCC) days at the selected centers. Data collection was carried out as the mothers waited to see the Healthcare providers in the queues.

\section{Measuring adherence to optimal infant feeding}

We defined optimal infant feeding as initiation of optimal IYCF within the first hour following birth in the form of exclusive breastfeeding up to 6 months followed by continued breastfeeding for up to 2 years and beyond with appropriate complementary foods after completion of 6 months is the gold standard for optimal $\mathrm{IYCF}^{1,4}$.

We established a scale to assess IYCF using four questions that cover the definition of IYCF, these included: (i) Breastfed within the first hour after delivery (ii) Were you able to breastfeed up to 6 months? (iii) Continue to breastfeed after introducing others foods to baby and (iv) for how long? For question i, ii and iii, option yes was score 1 while option no was scored zero. For question 5, option (a) was scored 1, option two was scored 2 while option three was scored 3 (Table 2). This lead to a maximum adherence range of 6 and a minimum of 0 . Adherence was then categorized into "non-adherence and adherence" subscales. Non-adherence ranged from 0 to 2 while adherence ranged from 3 to 6 .

\section{Data processing and analysis}

The data was entered, cleaned and analyzed by SPSS version 16.0 statistical packages. Descriptive summary statistics were used to describe the respondents' characteristics while appropriate statistical analysis was performed to assess the factors associated with adherence to infant feeding.

\section{Results}

264 participants were invited to participate in the study, $100 \%$ of these fully completed the survey.

\section{Socio-demographic characteristics of the participants}

Majority of the mothers were aged 20 to 34 years (80.3\%). Most of the mothers had at least 1 to 3 children (70.8) (Table 1) and had currently delivered female babies compared to male ones. The most common level of education attained by the mothers was primary education. With regards to occupation and average monthly income, most mothers were housewives (63.3\%)and earned an average monthly income of 100,000 to 300,000 Uganda Shillings (equivalent to $\$ 26$ to $\$ 78$ at time of publication) (Table 1). 


\begin{tabular}{|c|c|c|c|c|}
\hline \multicolumn{2}{|l|}{ Characteristics } & \multirow{2}{*}{$\begin{array}{l}\text { Frequency } \\
33 \\
212 \\
19\end{array}$} & \multirow{2}{*}{$\begin{array}{l}\text { Percentage } \\
12.5 \\
80.3 \\
7.2\end{array}$} & \multirow{2}{*}{$\begin{array}{l}\text { p-value } \\
<0.01\end{array}$} \\
\hline Age of mothers & $\begin{array}{l}15 \text { to } 19 \\
20-34 \\
>35\end{array}$ & & & \\
\hline Number of children & $\begin{array}{l}1 \text { to } 3 \\
>3\end{array}$ & $\begin{array}{l}187 \\
77\end{array}$ & $\begin{array}{l}70.8 \\
29.2\end{array}$ & 0.23 \\
\hline Sex of infant & $\begin{array}{l}\text { Male } \\
\text { Female }\end{array}$ & $\begin{array}{l}122 \\
142\end{array}$ & $\begin{array}{l}46.2 \\
53.8\end{array}$ & $<0.01$ \\
\hline Mothers' level of education & $\begin{array}{l}\text { Primary } \\
\text { Secondary } \\
\text { Tertiary }\end{array}$ & $\begin{array}{l}129 \\
109 \\
26\end{array}$ & $\begin{array}{l}48.9 \\
41.3 \\
9.8\end{array}$ & $<0.01$ \\
\hline Occupation of mother & $\begin{array}{l}\text { Peasant farmer } \\
\text { House Wife } \\
\text { Civil Servant } \\
\text { Business Woman }\end{array}$ & $\begin{array}{l}39 \\
167 \\
26 \\
32\end{array}$ & $\begin{array}{l}14.8 \\
63.3 \\
9.8 \\
12.1\end{array}$ & $<0.01$ \\
\hline $\begin{array}{l}\text { Average monthly income } \\
\text { of the family in Uganda } \\
\text { Shillings }\end{array}$ & $\begin{array}{l}<100,000 \\
100,000 \text { to } 300,000 \\
>300,000\end{array}$ & $\begin{array}{l}89 \\
134 \\
41\end{array}$ & $\begin{array}{l}33.7 \\
50.8 \\
15.5\end{array}$ & $<0.01$ \\
\hline Religion & $\begin{array}{l}\text { Muslim } \\
\text { Catholic } \\
\text { Protestant } \\
\text { Adventist }\end{array}$ & $\begin{array}{l}49 \\
103 \\
99 \\
13\end{array}$ & $\begin{array}{l}18.6 \\
39 \\
37.5 \\
4.9\end{array}$ & 0.34 \\
\hline Religion encourages BF & Yes & 264 & 100 & \\
\hline Marital status & $\begin{array}{l}\text { Married } \\
\text { Single } \\
\text { Separated }\end{array}$ & $\begin{array}{l}172 \\
78 \\
14\end{array}$ & $\begin{array}{l}65.2 \\
29.5 \\
5.3\end{array}$ & 0.75 \\
\hline $\begin{array}{l}\text { Husband's opinion on } \\
\text { breastfeeding }\end{array}$ & $\begin{array}{l}\text { Encouraging } \\
\text { Discouraging } \\
\text { Don't know }\end{array}$ & $\begin{array}{l}188 \\
6 \\
70\end{array}$ & $\begin{array}{l}71.2 \\
2.3 \\
26.5\end{array}$ & 0.46 \\
\hline $\begin{array}{l}\text { Kind of support from } \\
\text { community members }\end{array}$ & $\begin{array}{l}\text { Positioning of baby } \\
\text { Information on BF } \\
\text { Preparing feeds } \\
\text { Providing balanced diet } \\
\text { None }\end{array}$ & $\begin{array}{l}13 \\
26 \\
33 \\
13 \\
179\end{array}$ & $\begin{array}{l}4.9 \\
9.8 \\
12.5 \\
4.9 \\
61.2\end{array}$ & 0.27 \\
\hline
\end{tabular}

Source: primary data. BF: Breastfeeding

\section{Table 2. Adherence to IYCF.}

\begin{tabular}{|l|l|l|l|}
\hline Characteristics & Attributes & Frequency & Percentage \\
\hline $\begin{array}{l}\text { Breastfed within the first hour after } \\
\text { delivery }\end{array}$ & Yes & 188 & 71.2 \\
\hline Were you able to breast upto 6 months? & No & 76 & 28.8 \\
\hline & No & 213 & 80.7 \\
\hline $\begin{array}{l}\text { Continue to breastfeed after introducing } \\
\text { others foods to baby }\end{array}$ & Yes & 51 & 19.3 \\
\hline If yes, how long & No & 251 & 95.1 \\
& for less than 1 year & 13 & 4.9 \\
\hline & for one year & 148 & 4.9 \\
\hline 2 years and beyond & 90 & 34.1 \\
\hline
\end{tabular}

Source: primary data 
Adherence to IYCF practices

Practices that reflect mother's adherence to IYCF are shown in Table 2 below. The majority of the mothers $(71.2 \%)$ reported that they initiated breastfeeding within the first hour following delivery. Most mothers $(80.7 \%)$ also reported that they were able to breast upto 6 months (Table 2).

Regarding breastfeeding alongside complementary feeding after six months, almost all mothers $(95.1 \%)$ reported that they were able to continue breastfeeding with complementary feeding after six months. Among those that were able to do so $(n=251)$, the majority reported that they were able to breastfeed alongside complementary feeding upto one year (61\%), followed by those who reported they were able to breastfeed alongside complementary feeding for two years and beyond.
After scoring each participant using the four characteristics in Table 2, the majority of the participants were adherent $(n=210$, $79.6 \%)$ to IYCF practices while $54(20.4 \%)$ were non-adherent to IYCF practices (Table 2).

Maternal related characteristics of the respondents

The majority of the mothers reported that they were healthy during the antenatal care visits (ANC) period (61\%). Reasons reported to enable those who embraced optimal IYCF practices included; had plenty of breast milk (63.5\%), enough time with the baby (14.2\%) and encouragement from HCWs $(22.3 \%)$. Those who were unable to abide by optimal IYCF practices $(21.6 \%)$ reported reasons such as lack of optimal breast milk production (68.7\%) and plenty of cow's milks (31.3\%) (Table 3).

Table 3. Maternal related characteristics of the respondents $(n=264)$.

\begin{tabular}{|c|c|c|c|c|}
\hline Characteristics & Attributes & Frequency & Percentage & p-value \\
\hline Health status during pregnancy & $\begin{array}{l}\text { HIV positive } \\
\text { Sickly } \\
\text { Healthy }\end{array}$ & $\begin{array}{l}71 \\
32 \\
161\end{array}$ & $\begin{array}{l}26.9 \\
12.1 \\
61\end{array}$ & $<0.01$ \\
\hline What enable you to breastfeed $(n=188)^{\star}$ & $\begin{array}{l}\text { Plenty of breast milk } \\
\text { Enough time with baby } \\
\text { Encouragement from HCWs }\end{array}$ & $\begin{array}{l}129 \\
19 \\
39\end{array}$ & $\begin{array}{l}69 \\
10.2 \\
20.9\end{array}$ & 0.32 \\
\hline $\begin{array}{l}\text { What disable you from breast feeding } \\
(n=76)^{*}\end{array}$ & $\begin{array}{l}\text { Lack of breast milk } \\
\text { Was in pain }\end{array}$ & $\begin{array}{l}56 \\
20\end{array}$ & $\begin{array}{l}73.7 \\
26.3\end{array}$ & 0.53 \\
\hline $\begin{array}{l}\text { What is the right age for introducing } \\
\text { other food to baby }\end{array}$ & $\begin{array}{l}3 \text { to } 5 \text { months } \\
4 \text { to } 6 \text { months } \\
6 \text { months } \\
>6 \text { months }\end{array}$ & $\begin{array}{l}39 \\
32 \\
142 \\
50\end{array}$ & $\begin{array}{l}14.8 \\
12.1 \\
54.2 \\
18.9\end{array}$ & $<0.05$ \\
\hline Benefits of optimal IYCF & $\begin{array}{l}\text { Immunity for the baby } \\
\text { Bonding } \\
\text { Proper growth and development } \\
\text { Protects mother from OC }\end{array}$ & $\begin{array}{l}110 \\
6 \\
135 \\
13\end{array}$ & $\begin{array}{l}41.7 \\
2.4 \\
51.1 \\
4.9\end{array}$ & $<0.05$ \\
\hline $\begin{array}{l}\text { Do you know how to prepare nutritious } \\
\text { foods for the baby }\end{array}$ & $\begin{array}{l}\text { yes } \\
\text { no }\end{array}$ & $\begin{array}{l}90 \\
174\end{array}$ & $\begin{array}{l}34.1 \\
65.9\end{array}$ & $<0.05$ \\
\hline $\begin{array}{l}\text { Reasons for failure to prepare nutritious } \\
\text { feeds for the baby }(n=174)^{\star}\end{array}$ & $\begin{array}{l}\text { I don't know how to prepare it } \\
\text { lack of resources } \\
\text { baby dislike it }\end{array}$ & $\begin{array}{l}162 \\
6 \\
6\end{array}$ & $\begin{array}{l}93.1 \\
3.4 \\
3.4\end{array}$ & 0.85 \\
\hline Is first milk from mother nutritious & $\begin{array}{l}\text { Yes } \\
\text { Don't know }\end{array}$ & $\begin{array}{l}251 \\
13\end{array}$ & $\begin{array}{l}95.1 \\
4.9\end{array}$ & 0.21 \\
\hline $\begin{array}{l}\text { Is it possible for a mother to breastfeed } \\
\text { upto } 2 \text { years? }\end{array}$ & $\begin{array}{l}\text { Yes } \\
\text { No }\end{array}$ & $\begin{array}{l}141 \\
123\end{array}$ & $\begin{array}{l}53.4 \\
46.6\end{array}$ & 0.08 \\
\hline If no, why? & $\begin{array}{l}\text { Fear of sagging breasts } \\
\text { Work demand } \\
\text { Health conditions } \\
\text { Baby will refuse to eat food }\end{array}$ & $\begin{array}{l}55 \\
29 \\
39 \\
10\end{array}$ & $\begin{array}{l}40.9 \\
17.3 \\
35.5 \\
6.4\end{array}$ & 0.30 \\
\hline If yes, why? & $\begin{array}{l}\text { Nitrous } \\
\text { For proper growth }\end{array}$ & $\begin{array}{l}58 \\
32\end{array}$ & $\begin{array}{l}64.4 \\
35.6\end{array}$ & 0.42 \\
\hline If no, why? & $\begin{array}{l}\text { I don't know how to prepare it } \\
\text { Lack of resources } \\
\text { Baby dislike it }\end{array}$ & $\begin{array}{l}162 \\
6 \\
6\end{array}$ & $\begin{array}{l}93.1 \\
3.4 \\
3.4\end{array}$ & 0.94 \\
\hline $\begin{array}{l}\text { How many times in a day do you feed a } \\
\text { baby on solid or semi solid foods }\end{array}$ & $\begin{array}{l}2 \\
3 \text { to } 4\end{array}$ & $\begin{array}{l}226 \\
38\end{array}$ & $\begin{array}{l}85.6 \\
14.4\end{array}$ & 0.47 \\
\hline
\end{tabular}

OC: Ovarian Cancer; HCWs: Healthcare Worker 
Regarding awareness on the time for introduction of complementary feeding, less than a third of the mother reported the optimum ITCF time for starting complementary feeding. Various benefits of optimal IYCF were reported by the respondents, these include; immunity for the baby, proper growth and development, bonding, protection of the mother from ovarian cancer (Table 3). Most mothers reported that it is possible to breastfeed up to 2 years while most mothers were not aware of how to prepare nutritious complementary food for the baby after 6 months. Reasons for failure to prepare nutritious food for the babies include; lack of awareness on how to prepare foods for the baby, lack of resources and some mothers reported that often the babies dislike the food (Table 3).

\section{Health care provider practices}

All mothers reported that they attended ANC. Information received during ANC visits include; positioning of the baby during breastfeeding, benefits of breastfeeding, how to feed an infant using a cup, importance of Colostrum and time of initiating breastfeeding. Majority of the mothers (53.4\%) reported that they did not received practical demonstration during ANC visits. Different forms of support were reported to have been received immediately after birth. These include; initiating breastfeeding within one hour $(40.1 \%)$, positioning of the newborn during breastfeeding and expressing of breast milk. Mothers reported that they received various health education talks during YCC visits, these included talks on; exclusive breast feeding, duration of breastfeeding and complementary feeding, and the benefits of breastfeeding (Table 4).
At bivariate analysis, age, number of children, sex of the infant, mothers level of education, occupation and average monthly income were significantly associated with optimal infant feeding $(\mathrm{P}<0.05)$ (Table 1).

Maternal characteristics such as health status during labor, situations that enable mothers to breastfeed during first hour following delivery, perception of importance of first breast milk, awareness of the right age to introduce feeds, perceived benefits of breastfeeding, and knowing how many times in a day a baby is supposed to breastfeed were significant predictors of adherence to optimal infant feeding $(\mathrm{P}<0.05)$ (Table 3$)$.

Health care related characteristics such as information received on infant feeding during $\mathrm{ANC}$, the kind of information received, practical support received during ANC and counseling of mothers on infant feeding during ANC visits were significant determinants of adherence to optimal infant feeding $(\mathrm{p}<0.05)$. While receiving practical support was not significantly associated with optimal feeding ( $\mathrm{p}=0.998)$ (Table 4).

Multivariate analysis was performed to determine independent predictors of adherence to optimal IYCF. It was revealed that the age of the mother, level of education, average monthly of the family, health condition of the mother during pregnancy, awareness of the right age to introduce complementary food and having received information on IYCF during ANC visits were independent predictors of adherence to optimal IYCF practices.

Table 4. Health care related practices reported by the mothers.

\begin{tabular}{|c|c|c|c|c|}
\hline \multicolumn{2}{|l|}{ Characteristics } & \multirow{2}{*}{$\begin{array}{l}\text { Frequency } \\
160 \\
78 \\
26\end{array}$} & \multirow{2}{*}{$\begin{array}{l}\text { Percentage } \\
60.6 \\
29.6 \\
9.8\end{array}$} & \multirow{2}{*}{\begin{tabular}{|l|} 
p-value \\
0.002
\end{tabular}} \\
\hline $\begin{array}{l}\text { Received information on IYCF } \\
\text { during ANC visits }\end{array}$ & $\begin{array}{l}\text { Yes } \\
\text { No } \\
\text { Don't Know }\end{array}$ & & & \\
\hline $\begin{array}{l}\text { Information received during ANC } \\
\text { Visits }\end{array}$ & $\begin{array}{l}\text { Positioning of the baby } \\
\text { Benefits of BF } \\
\text { How to feed using a cup } \\
\text { Importance of Colostrum } \\
\text { Time of initiating BF }\end{array}$ & $\begin{array}{l}6 \\
109 \\
26 \\
26 \\
96\end{array}$ & $\begin{array}{l}2.3 \\
41.3 \\
9.8 \\
9.8 \\
36.7\end{array}$ & 0.000 \\
\hline $\begin{array}{l}\text { Receive practical demonstrations } \\
\text { during ANC Visits }\end{array}$ & $\begin{array}{l}\text { Yes } \\
\text { No }\end{array}$ & $\begin{array}{l}123 \\
141\end{array}$ & $\begin{array}{l}46.6 \\
53.4\end{array}$ & 0.998 \\
\hline $\begin{array}{l}\text { Form of practical support } \\
\text { received immediately after birth }\end{array}$ & $\begin{array}{l}\text { Initiation of BF } \\
\text { Breastfeeding Position } \\
\text { Expressing breast milk }\end{array}$ & $\begin{array}{l}65 \\
71 \\
26\end{array}$ & $\begin{array}{l}40.1 \\
43.8 \\
16.4\end{array}$ & 0.52 \\
\hline Health talks during YCC clinics & $\begin{array}{l}\text { Exclusive breast feeding } \\
\text { Duration of BF and CF and } \\
\text { Complementary feeding } \\
\text { Benefits of BF }\end{array}$ & $\begin{array}{l}13 \\
33 \\
39\end{array}$ & $\begin{array}{l}15.3 \\
38.8 \\
45.9\end{array}$ & $<0.01$ \\
\hline
\end{tabular}

Source: primary data. BF: Breastfeeding. CF: Complementary feeding 


\section{Discussion}

In this study, majority of the participants were adherent (79.6\%) to IYCF practices while $20.4 \%$ were non-adherent to IYCF practices. This could be attributed to well-established strategies facilitating optimal IYCF in Uganda. Indeed, numerous campaigns and policies are in place in support of optimal IYCF in Uganda. These include, but are not limited to, activities involving frontline healthcare providers such as nurses and midwives and ANC services. Optimal IYCF was reflected by assessing practices reflecting IYCF practices such as: breastfed within the first hour after delivery, ability to exclusively breastfeed upto 6 months, continue to breastfeed after introducing others foods to baby and recommended duration of breastfeeding post introduction of complementary feeding ${ }^{14}$. This is also in line with the WHO published set of population-level IYCF indicators of appropriate feeding practices in children ages 6-23 months ${ }^{1}$.

Infant feeding practices in this study were appropriate with regards to the WHO criteria for optimal IYCF practices. This finding is contrary to that reported in a study in Kenya in Urban informal settlements in Nairobi that reported inappropriate IYCF practices $^{11}$. Optimal IYCF practices such as breast feeding have been reported to be high in Uganda compared to other Sub-Saharan African Countries like Nigeria and Niger'. This finding supports the findings of this study of a good estimate of optimal IYCF practices. There were significantly more mothers who reported to have initiated $\mathrm{BF}$ within an hour compared to less than half reported in a similar study in India ${ }^{15}$.

In context of characteristics of the sample, socio-demographic and economic characteristics of the participants in this study were similar to those reported form the recent population census in Uganda $^{12}$. This makes our findings generalizable to the entire population with minimal limitations. The majority of the mothers were aged 20 to 34 years, this is attributed to the fact that majority of the reproductive population in Uganda lies within this age group. Most of the mothers had at least 1 to 3 children. This finding is in line with the fertility rate reported in Uganda, owing to the fact that on average, each mother in Uganda has on average up to 7 children. There were comparatively more female babies compared to male ones, this is in line to the female to male ratios reported in the recent population of Uganda. The most common level of education attained by the mothers was primary education. Indeed, it has been estimated that at least majority of the Ugandan population has attained primary education ${ }^{12}$. With regards to occupation and average monthly income; most mothers were housewives and earned an average monthly income of 100,000 to 300,000 Uganda Shillings. This is in line with the economic characteristics of majority of the Ugandan population revealed in the recent census.

The reported breast feeding rate in this study is higher than that reported in World Breastfeeding Initiative: Uganda Assessment Report that showed that $40 \%$ of the children under 6 months of age have not been exclusively breastfed and only $52.5 \%$ were breastfed within an hour of birth.

Reasons reported to enable those who embraced initiation of BF with the first hour included; had plenty of breast milk production, enough time with the baby and encouragement from HCWs. Indeed, strong individual champions such as HCWs who encourage IYCF such as initiating BF in the first hour have been reported elsewhere as catalysts to optimal IYCF practices ${ }^{14,16}$. Engagement of the mother by providing enough time with the baby would in turn stimulate milk production. This could in part solve the problem of lack of breast milk production which was one of the barriers to initiating BF in the first hour. In addition, controlling for pain after delivery could go a long way in giving mothers more comfort post-delivery so that they could start enjoying happy times with the new born.

In context of initiating complementary feeding, few mothers in this study were aware of the right timing. Emphasis on the right timing and preparation of complementary feeds during ANC and PNC visits needs to be hastened in facility and community based programmes. Awareness of the benefits of BF was significant in this study.

Attendance of ANC was overwhelmingly high in this study. This could be attributed to programmes such as the Baby Friendly Hospital Initiative (See World Breastfeeding Trends Initiative, Uganda Report 2015). However; practical demonstrations need to be incorporated in the ANC visits. The majority of the mothers reported that they did not received practical demonstration during ANC visits. These could improve feeding behaviors of mothers and in turn sustain optimal IYCF practices upto a recommended time.

Correlates to adherence to optimal IYCF included sociodemographic factors such as; age of the mother, level of education and average monthly income of the family. A similar study that assessed the impact of Socio-demographic and health service factors on breastfeeding in SSA using demographic health survey data reported that educational attainment was a significant predictor of IYCF practices such as exclusive breast feeding ${ }^{8}$. Health condition of the mother during pregnancy, awareness of the right age to introduce complementary food and having received information on IYCF during ANC visits were independent predictors of adherence to optimal IYCF practices. We argue that to promote and sustain IYCF practices, it is imperative to create public awareness about appropriate complementary feeding, its timing and providing IYCF counseling support systems for mothers.

\section{Limitations of the study}

While as this study presents important information on the extent of adherence to IYCF practices in Uganda, the data was obtained using self-report from the mothers. Such information gained from self-report is liable to bias as we cannot ascertain the truthfulness of information provided. In addition, the findings of this study are obtained from a semi-urban setting, as such these finding could not be generalizable to mothers in urban settings who could have different socio-demographic and economic characteristics.

\section{Conclusion}

A significantly good adherence to optimal IYCF practices was revealed in this study. Promotion and sustaining well-established policies to support IYCF programmes is recommended to maintain optimal IYCF practices. In addition, practical demonstrations need to be incorporated in the ANC visits. 


\section{Ethical approval and consent}

The study proposal was approved by the Institute of Public Health and Health Management of Clarke International University. Permission to collect data from health facilities was granted by the District Health Officer (DHO) and the administrator in-charge of the health facilities. It was strictly voluntary to participate in the study and written informed consent was obtained from participants at all times.

\section{Data availability}

The data underlying this study is available from figshare. Dataset 1: A study on Factors influencing mothers' adherence to optimal and young child feeding practices for babies below two years in Mpigi town council, Mpigi district, Uganda. https://doi.org/10.6084/ m9.figshare.6470705.v1 $1^{17}$

This dataset is available under a $\mathrm{CC}$ by 4.0 license

Data points containing '999' or '99' denote missing variables. Additionally where respondents have answered yes or no, their answer in some cases prevents them from answering the next question and their for the subsequent analysis. '999/99' was used in case also.

\section{Author endorsement}

Masoomeh Imanipour confirms that the author has an appropriate level of expertise to conduct this research, and confirms that the submission is of an acceptable scientific standard. Masoomeh Imanipour declares they have no competing interests. Affiliation: Faculty of Nursing and Midwifery, Tehran University of Medical Sciences (TUMS), Tehran, Iran.

\section{Competing interests}

The authors declare that they have no competing interests.

\section{Grant information}

The author(s) declared that no funding was obtained in support of this work.

\section{Acknowledgements}

The authors wish to extend their deep appreciation to Mr. Alege JB, Dean of the Institute of Public Health and Management of Clarke International University.

\section{Supplementary material}

The questionnaire used in the study is available from figshare Supplementary File 1: Mothers' adherence to optimal infant and young child feeding practices in Uganda: a cross-sectional study https://doi.org/10.6084/m9.figshare.6468653.v1 ${ }^{13}$

Available under a CC by 4.0 license

1. Jones $A D$, Ickes $S B$, Smith LE, et al.: World Health Organization infant and young child feeding indicators and their associations with child anthropometry: a synthesis of recent findings. Matern Child Nutr. 2014; 10(1): 1-7. PubMed Abstract | Publisher Full Text

2. Sankar MJ, Sinha B, Chowdhury R, et al.: Optimal breastfeeding practices and infant and child mortality: a systematic review and meta-analysis. Acta Paediatr. 2015; 104(467): 3-13.

PubMed Abstract | Publisher Full Text

3. Black RE, Victora CG, Walker SP, et al:: Maternal and child undernutrition and overweight in low-income and middle-income countries. Lancet. 2013; 382(9890): 427-51.

PubMed Abstract | Publisher Full Text

4. Tiwari S, Bharadva K, Yadav B, et al.: Infant and Young Child Feeding Guidelines, 2016. Indian Pediatr. 2016; 53(8): 703-13. PubMed Abstract

5. Victor R, Baines SK, Agho KE, et al.: Determinants of breastfeeding indicators among children less than $\mathbf{2 4}$ months of age in Tanzania: a secondary analysis of the 2010 Tanzania Demographic and Health Survey. BMJ Open. 2013; 3(1): pii: e001529.

PubMed Abstract | Publisher Full Text | Free Full Text

6. Issaka Al, Agho KE, Page AN, et al.: Determinants of suboptimal complementary feeding practices among children aged 6-23 months in seven francophone West African countries. Matern Child Nutr. 2015; 11 Suppl 1: 31-52. PubMed Abstract | Publisher Full Text

7. Ogbo FA, Page A, Agho KE, et al.: Determinants of trends in breast-feeding indicators in Nigeria, 1999-2013. Public Health Nutr. 2015; 18(18): 3287-99. PubMed Abstract | Publisher Full Text

8. Ogbo FA, Page A, Idoko J, et al:: Trends in complementary feeding indicators in Nigeria, 2003-2013. BMJ Open. 2015; 5(10): e008467. PubMed Abstract | Publisher Full Text | Free Full Text

9. Ogbo FA, Agho KE, Page A: Determinants of suboptimal breastfeeding practices in Nigeria: evidence from the 2008 demographic and health survey. BMC Public Health. 2015; 15: 259.

PubMed Abstract | Publisher Full Text | Free Full Text

10. Nankumbi J, Muliira JK: Barriers to infant and child-feeding practices: a qualitative study of primary caregivers in Rural Uganda. $J$ Health Popul Nutr. 2015; 33(1): 106-16.

PubMed Abstract | Free Full Text

11. Macharia TN, Ochola S, Mutua MK, et al.: Association between household food security and infant feeding practices in urban informal settlements in Nairobi, Kenya. J Dev Orig Health Dis. 2018; 9(1): 20-29.

PubMed Abstract | Publisher Full Text | Free Full Text

12. Uganda Bureau of Statistics: The National Population and Housing Census 2014-Main Report. 2016.

Reference Source

13. Frank K, Zabinah N: Mothers' adherence to optimal infant and young child feeding practices in Uganda: a cross-sectional study. 2018. Publisher Full Text

14. Puri S: Transition in Infant and Young Child Feeding Practices in India. Curr Diabetes Rev. 2017; 13(5): 477-481. PubMed Abstract | Publisher Full Text

15. Nguyen PH, Avula R \& Menon P: Estimates of child deaths prevented from scaling up infant and young child feeding interventions in India 2016-2025. Matern Child Nutr. 2018; 14(S2).

16. Shaker-Berbari L, Ghattas H, Symon AG, et al.: Infant and young child feeding in emergencies: Organisational policies and activities during the refugee crisis in Lebanon. Matern Child Nutr. 2018. PubMed Abstract | Publisher Full Text

17. Frank K, Zabinah N: Dataset: A study on Factors influencing mothers' adherence to optimal and young child feeding practices for babies below two years in Mpigi town council, Mpigi district, Uganda. 2018. Publisher Full Text 


\section{Open Peer Review}

\section{Current Peer Review Status: $\mathrm{X} \times \mathrm{X}$}

\section{Version 1}

Reviewer Report 25 March 2019

https://doi.org/10.5256/f1000research.16482.r45356

(C) 2019 Soofi S et al. This is an open access peer review report distributed under the terms of the Creative Commons Attribution License, which permits unrestricted use, distribution, and reproduction in any medium, provided the original work is properly cited.

\section{Sajid Soofi}

Division of Woman and Child Health, Aga Khan University, Karachi, Pakistan

Shabina Ariff

Department of Pediatrics, Aga Khan University, Karachi, Pakistan

\section{Atif Habib}

Aga Khan University, Karachi, Pakistan

\section{Gul Nawaz}

The Aga Khan University, Karachi, Pakistan

This study was conducted to determine factors contributing towards mothers' adherence to optimal infant and young child feeding practices for children under 2 years. The study investigators adopted cross sectional design and purposive sampling methods. The data was collected at randomly-selected health centres. The authors reported baseline SES characteristics of study participants and mothers' characteristics. They also reported mothers' practices on few IYCF indicators. They presented simple descriptive analysis.

The authors did not provide analysis and discussion regarding the main objective of the study: factors influencing mothers' adherence to optimal IYCF practices for babies below two years. This study has limited scope and interest of audience at a larger scale. Further, the data collection tools used are not appropriate especially the question asked to determine EBF rates. The language needs some revision. The analysis section needs more elaboration.

This paper wouldn't be accepted for indexing as there are major issues in the paper and the authors need to do further analysis and then draw conclusions.

Is the work clearly and accurately presented and does it cite the current literature? Partly

Is the study design appropriate and is the work technically sound?

Partly 
Are sufficient details of methods and analysis provided to allow replication by others? No

If applicable, is the statistical analysis and its interpretation appropriate? No

Are all the source data underlying the results available to ensure full reproducibility? Yes

Are the conclusions drawn adequately supported by the results? Partly

Competing Interests: No competing interests were disclosed.

Reviewer Expertise: Public Health scientist with special interest in Nutrition

We confirm that we have read this submission and believe that we have an appropriate level of expertise to state that we do not consider it to be of an acceptable scientific standard, for reasons outlined above.

Reviewer Report 20 March 2019

https://doi.org/10.5256/f1000research.16482.r45357

(C) 2019 Amodu $O$ et al. This is an open access peer review report distributed under the terms of the Creative Commons Attribution License, which permits unrestricted use, distribution, and reproduction in any medium, provided the original work is properly cited.

\section{Olukemi K. Amodu}

Institute of Child Health, College of Medicine, University of Ibadan (UI), Ibadan, Nigeria Mofeyisara Omobowale

Institute of Child Health, College of Medicine, University of Ibadan (UI), Ibadan, Nigeria

The study was designed to identify the factors that influence mother's adherence to optimal infant and young feeding (IYCF) practices in Uganda. The authors used four characteristics: initiation of breastfeeding within the first hour following birth; exclusive breastfeeding up to 6 months; continued breastfeeding with appropriate complementary foods up to 2 years and beyond to assess IYCF. The study however has some deficiencies.

1. The question, "Were you able to breastfeed up to 6 months?" did not take into consideration adherence to breastfeeding for 6 months. Adherence was a key factor in this study and this deficiency weakened the design and results.

2. The other question that would have also helped is "when did you introduce complementary feeding?". This would have helped clarify results.

3. The statistics were not extensive. The method section needs further explanation. 
4. The discussion is weak and not well written. The results were not well discussed. There is need to properly link and discuss the findings from demographic information to other findings. Findings from other studies are not discussed.

5. There are grammatical errors in the article. Run-off statements and unclear sentences need editing. Engaging editors' service will be helpful to the manuscript.

6. Data from 264 respondents cannot be generalized for a country with over 44 million population. There is the need to review this in the discussion.

7. The meaning and importance of P-value in each of the tables presented needs explanation.

Is the work clearly and accurately presented and does it cite the current literature? Partly

Is the study design appropriate and is the work technically sound? Partly

Are sufficient details of methods and analysis provided to allow replication by others? Yes

If applicable, is the statistical analysis and its interpretation appropriate? Partly

Are all the source data underlying the results available to ensure full reproducibility? Yes

Are the conclusions drawn adequately supported by the results? Partly

Competing Interests: No competing interests were disclosed.

Reviewer Expertise: Genetics/Public Health

We confirm that we have read this submission and believe that we have an appropriate level of expertise to state that we do not consider it to be of an acceptable scientific standard, for reasons outlined above.

Reviewer Report 24 September 2018

https://doi.org/10.5256/f1000research.16482.r38277

(c) 2018 Puri S. This is an open access peer review report distributed under the terms of the Creative Commons Attribution License, which permits unrestricted use, distribution, and reproduction in any medium, provided the original work is properly cited. 


\section{Seema Puri}

Institute of Home Economics, University of Delhi, New Delhi, Delhi, India

The article brings out the IYCF practices in a town of Uganda. It reports the profile of the mothers, their access to healthcare as well the adherence to suitable IYCF practices.

While the authors have defined optimal IYCF as initiation of breastfeeding within the first hour following birth, exclusive breastfeeding up to 6 months followed by continued breastfeeding for up to 2 years and beyond with appropriate complementary foods after completion of 6 months, their scale to assess IYCF based on 4 questions does not cover these issues. For example, exclusive breastfeeding up to 6 months is not asked; instead the question is "Were you able to breastfeed up to 6 months?" - the concept of exclusive breastfeeding is lost. Since this is the basis of defining adherence, the whole data categorization becomes faulty, and hence subsequent analysis to study correlates of IYCF also are biased.

What do the $P$ values displayed in Table 3 onwards imply? This was not given in the discussion.

Also in Table 4, many of the questions are multiple responses and therefore cannot add up to $100 \%$ nor can any statistical test be applied to them.

No details of multivariate analysis given.

Language errors need to be corrected.

Is the work clearly and accurately presented and does it cite the current literature? Partly

Is the study design appropriate and is the work technically sound?

Partly

Are sufficient details of methods and analysis provided to allow replication by others? Partly

If applicable, is the statistical analysis and its interpretation appropriate? Partly

Are all the source data underlying the results available to ensure full reproducibility? Yes

Are the conclusions drawn adequately supported by the results? Partly

Competing Interests: No competing interests were disclosed.

Reviewer Expertise: Infant and young child nutrition , clinical nutrition

I confirm that I have read this submission and believe that I have an appropriate level of 
expertise to state that I do not consider it to be of an acceptable scientific standard, for reasons outlined above.

The benefits of publishing with F1000Research:

- Your article is published within days, with no editorial bias

- You can publish traditional articles, null/negative results, case reports, data notes and more

- The peer review process is transparent and collaborative

- Your article is indexed in PubMed after passing peer review

- Dedicated customer support at every stage

For pre-submission enquiries, contact research@f1000.com 